\title{
Kebiljakan REDD+
}

Kebijakan REDD+ mengamati bagaimana REDD+ tengah berlangsung di arena kebijakan nasional.

Tujuan REDD+ secara keseluruhan adalah untuk membantu memitigasi perubahan iklim global, dengan menciptakan insentif bagi berbagai negara untuk mengurangi emisi gas rumah kaca yang disebabkan oleh deforestasi dan degradasi hutan.

Namun agar REDD+ dapat mewujudkan potensi mitigasi secara penuh, maka pemicu deforestasi dan degradasi hutan harus diatasi. Caranya termasuk melakukan reformasi di bidang kebijakan, berbagai praktik dan proses pada tingkat nasional.

Pemerintah nasional di negara-negara pelaksana REDD+ mengadaptasi atau memperkenalkan kebijakan yang relevan. Namun sejauh mana kebijakan tersebut akan efektif atau tidak ditentukan oleh berbagai faktor: perilaku aktor-aktor politik, bagaimana para aktor memahami dan merespon REDD+, bagaimana kelembagaan dibentuk, serta peraturan-peraturan dan praktik yang ada.

Dengan menganalisis pemicu, perantara, institusi dan wacana publik yang membentuk konteks REDD+ di beberapa negara, kami berupaya untuk memahami perubahan apa yang diperlukan untuk menciptakan sistem REDD+ dengan hasil yang efektif, efisien dan berkeadilan, dan bagaimana perubahan ini dapat terwujud.

\section{Studi Komparatif Global tentang REDD+}

\section{ForestsClimateChange.org}




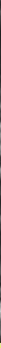

\section{Deforestasi tidak hanya terkait dengan sektor kehutanan}

Beberapa kebijakan di luar sektor kehutanan secara tidak langsung memicu deforestasi dan degradasi hutan. Kebijakan ini termasuk sektor pembangunan nasional, sasaran energi dan ketahanan pangan, dan dukungan yang kuat bagi industri-industri ekstraktif. Kebijakan tersebut acap kali dilandaskan pada paradigma umum dalam pembangunan nasional yang berlaku dan kerangka atau tujuan kebijakan yang ada, yang mencerminkan "cara pencapaian yang selama ini dilakukan", sehingga segala tantangan akan menjadi kontroversial dan menemui perlawanan. Kerangka kerja yang ada dapat menyatukan peraturan dan kebijakan yang mendukung REDD $+{ }^{1}$, namun untuk melucuti struktur kekuasaan dan perilaku mencari keuntungan yang ada akan memerlukan reformasi besar-besaran.

\section{Status Quo lebih berkuasa dan menolak perubahan}

Dalam banyak hal, kepentingan ekonomi yang kuat dan struktur kekuasaan berada di balik sejumlah pemicu utama deforestasi: mereka memperkuat status quo dan menciptakan penghambat untuk berubah. ${ }^{2} \mathrm{Di}$ banyak negara, pemicu utama deforestasi terkait dengan rente yang sangat tinggi. ${ }^{1}$ Perusahaan-perusahaan komersial berskala besar, khususnya, yang memegang kekuasaan cukup besar dengan melibatkan kekayaan dan hubungan dekat dengan struktur birokrasi dan negara pun memiliki kepentingan ekonomis dan politik terhadap eksploitasi dan konversi hutan. Hal ini berarti, sejumlah aktor politik dan ekonomi yang berkuasa akan memilih untuk melanjutkan "bisnis seperti biasa". ${ }^{3}$

\section{Implementasi Kebijakan REDD+ menghadapi berbagai kendala}

Mencapai perubahan transformasi ${ }^{1}$ akan mencakup hal-hal berikut:

- Kurangnya koordinasi, baik vertikal maupun horizontal, di antara lembaga-lembaga pemerintah, yang memperbesar biaya transaksi dan menghambat upaya-upaya untuk melintasi batas-batas sektoral;

- terbatasnya keterlibatan kelompok-kelompok rentan, yang mengakibatkan keterwakilan yang tidak memadai, ketidaksetaraan dan kemungkinan terjadinya konflik';

- Korupsi dan perampasan lahan dan manfaat oleh para elit yang menyebabkan ketidakefektifan kebijakan dan mengarahkan pada ketidakadilan, inefisiensi dan kemungkinan terjadinya konflik;

- Terbatasnya otonomi negara dari kepentingan sektor swasta yang berkuasa;

- aktor-aktor internasional sebagai faktor pendorong tunggal, yang mengakibatkan kurangnya rasa kepemilikan nasional dan mempersulit perumusan dan penerapan kebijakan REDD+ nasional secara lebih efektif';

- Rendahnya kapasitas administratif dan teknis membatasi kemampuan negara untuk menerapkan dan menegakkan kebijakan, hukum dan keuangan atau sistem pengelolaan lainnya.

Insentif ekonomi dan informasi yang baru, dan meningkatnya kekhawatiran publik tentang perubahan iklim, serta aktoraktor dan koalisi yang baru semua ini berpotensi untuk memunculkan perubahan transformatif.
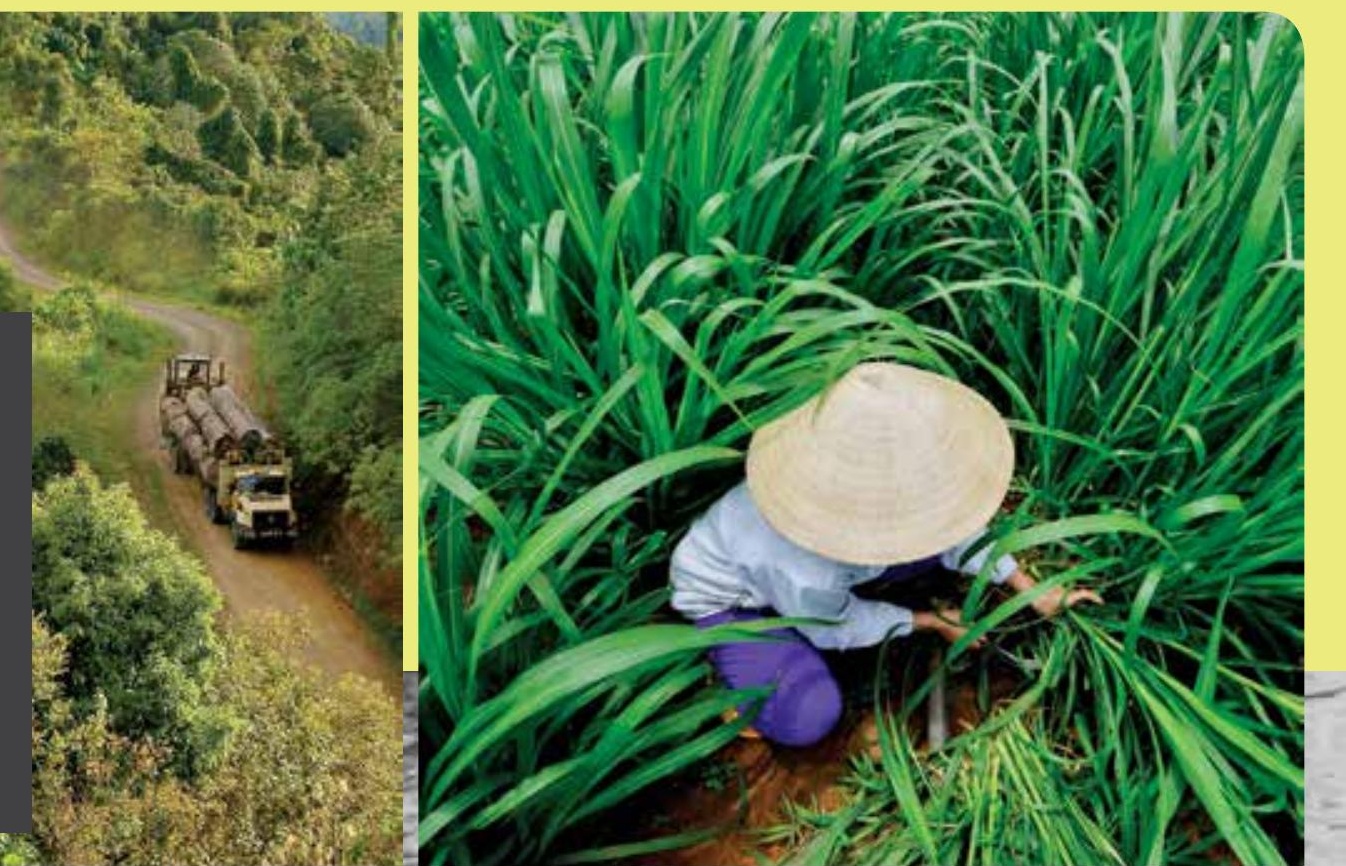


\section{Daftar Pustaka}

1 Di Gregorio M, Brockhaus M, Cronin T dan Muharrom E. 2012. Politics and power in national REDD+ policy processes. Dalam Angelsen A, Brockhaus M, Sunderlin W dan Verchot LV, eds. Analysing REDD+: Challenges and Choices. Bogor, Indonesia: CIFOR. 69-90.

2 Brockhaus M dan Angelsen A. 2012. Seeing REDD+ through 4ls: A political economy framework. Dalam Angelsen A, Brockhaus M, Sunderlin W dan Verchot LV, eds. Analysing REDD+: Challenges and Choices. Bogor, Indonesia: CIFOR. 15-30.

3 Brockhaus M, Di Gregorio M dan Mardiah S. 2013. Governing the design of national REDD+: An analysis of the power of agency. Forest Policy and Economics doi: 10.1016/j.forpol.2013.07.003

4 Luttrell C, Resosudarmo IAP, Muharrom E, Brockhaus M dan Seymour F. 2012. The political context of REDD+ in Indonesia: Constituencies for change. Environmental Science \& Policy 35: 67-75 doi: 10.1016/j.envsci.2012.10.001

\section{Bacaan lebih lanjut}

Angelsen A dan Rudel TK. 2013. Designing and implementing effective REDD+ policies: A forest transition approach. Review of Environmental Economics and Policy 7(11):91-113.

Assembe-Mvondo A, Brockhaus M dan Lescuyer G. 2013. Assessment of the effectiveness, efficiency and equity of benefit-sharing schemes under large scale agriculture: Lessons from land fees in Cameroon. European Journal of Development and Research 25:641-56.

Brockhaus M dan di Gregorio M. 2012. A brief overview: Component 1 on national REDD+ policies and processes. CIFOR Infobrief 13. Bogor, Indonesia: CIFOR.

Brockhaus M, di Gregorio M dan Wertz-Kanounnikoff S. 2012. Guide for country profiles: Global Comparative Study on REDD (GCS-REDD) Component 1 on National REDD+ Policies and Processes. Bogor, Indonesia: CIFOR.

Brockhaus M, Obidzinski K, Dermawan A, Laumonier Y dan Luttrell C. 2012. An overview of forest and land allocation policies in Indonesia: Is the current framework sufficient to meet the needs of REDD+? Forest Policy and Economics 18:30-37.

Di Gregorio M, Brockhaus M, Cronin T, Muharrom E, Santoso L, Mardiah S dan Büdenbender M. 2013. Equity and REDD+ in the media: A comparative analysis of policy discourses. Ecology and Society 18(2):39.

Di Gregorio M, Price S, Saunders C dan Brockhaus M. 2012. Code book for the analysis of media frames in articles on REDD. Bogor, Indonesia: CIFOR.

Korhonen-Kurki K, Brockhaus M, Duchelle A, Atmadja S, Pham TT dan Schofield L. 2013. Multiple levels and multiple challenges for measurement, reporting and verification of REDD+. International Journal of the Commons 7(2). http://www.thecommonsjournal.org/index.php/ijc/article/view/372/348

Korhonen-Kurki K, Sehring J, Brockhaus M dan Di Gregorio M. 2014. Enabling factors for establishing REDD+ in a context of weak governance. Climate Policy 14(2):167-186.

Larson AM, Brockhaus M, Sunderlin WD, Duchelle A, Babon A, Dokken T, Pham TT, Resosudarmo IAP, Selaya G, Awono A dan Huynh T. 2013. Land tenure and REDD+: The good, the bad and the ugly. Global Environmental Change 23(3): 678-89.

Luttrell C, Loft, L, Gebara, MF, Kweka, D, Brockhaus, M, Angelsen, A dan Sunderlin, WD. 2013. Who should benefit from REDD+? Rationales and realities. Ecology and Society 18(4): 52.

Pacheco P, Putzel P, Obidzinski K dan Schoneveld G. 2012. REDD+ and the global economy: Competing forces and policy options. Dalam Angelsen A, Brockhaus M, Sunderlin W dan Verchot LV, eds. Analysing REDD+: Challenges and Choices. Bogor, Indonesia: CIFOR. 51-66.

Foto oleh:

Ollivier Girard (sampul, bagian dalam), Neil Palmer, Jan Van Der Ploeg

Disusun sebagai bagian dari:

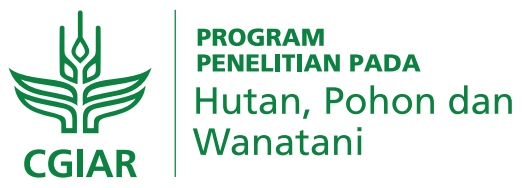
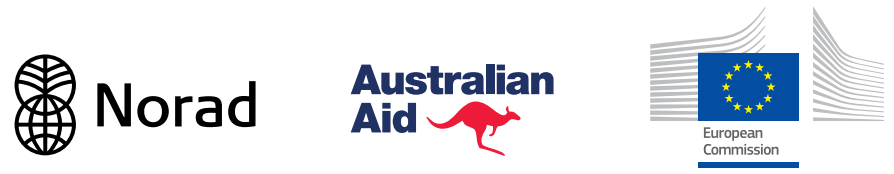

Schweizerische Eidgenossenschaft Confédération suisse Confederazione Svizzera Confederaziun svizra

Swiss Agency for Development and Cooperation SDC

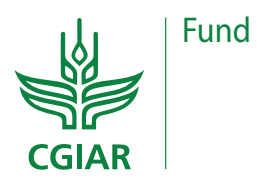

Federal Ministry for the Environment, Nature Conservation and Nuclear Safety 